\title{
Nutritional values of chironomid larvae grown in palm oil mill effluent and algal culture
}

\begin{abstract}
Chironomid larvae were grown in nine 70-1 tanks containing palm oil mill effluent (POME) and algol culture. The algol culture was obtained by inoculating $200 \mathrm{ml}$ pure culture of Chlorella vulgaris Beijerinck initially in 20-1 tap water containing inorganic fertilizer N:P:K (1:0.2:0.2). Each treatment was done in triplicate. Dissolved oxygen, $\mathrm{pH}$, total nitrogen, total ammonia nitrogen, ortho-phosphate, chemical oxygen demand (COD), total suspended solids and total dissolved solids of the media in each tank were analyzed. Protein, lipid ash, amino acids, fatty acids, total carotene and minerals were determined for POME, chironomid larvae, and algae. The culture was terminated after 25 days and chironomid production was determined. The production of chironomid larvae was significantly $(\mathrm{P}<0.01)$ higher in POME tanks (580 g/20 1 POME) than in algal culture (35 g/20 1 algal culture). Raw palm oil mill effluents contained significantly higher $(\mathrm{P}<0.05)$ arginine, methionine, isoleucine and phenylalanine than algae grown in fertilizer. The essential amino acids of chironomid larvae grown in POME such as histidine, arginine, methionine, isoleucine, phenylalanine and lysine were significantly $(\mathrm{P}<0.05)$ higher than in chironomid larvae grown on algal culture. The polyunsaturated fatty acids (PUFA) with the exception of Y-linolenic acid (18:3n-6), were higher in chironomid larvae grown in POME than those grown on algal culture. Twenty seven minerals were detected by electron microscope but 23 minerals were analyzed and quantified in POME, algae, and chironomid larvae grown in POME and algol culture. The quantity of sulfur was significantly higher $(\mathrm{P}<0.05)$ in POME than algae, which probably induced the synthesis of methionine, a S-containing essential amino acid in chironomid larvae cultured in POME. Experiments showed that POME did not only induce high production of chironomid larvae, but also produced high quality live food for the aquaculture industry.
\end{abstract}

Keyword: Algae; Amino acids; Chironomid larvae; Effluent; Minerals; Unsaturated fatty acids 